\title{
Impact of Mobile Learning on Distance Education
}

\author{
Yongbin Zhou \\ BaiCheng Normal University \\ 84625006@qq.com
}

\begin{abstract}
Mobile learning is another new learning model following the emergence of digital learning, and a new research hotspot in the field of education technology. How to make effective use of mobile communications technology to assist the all types of teaching and learning has become the research center of mobile learning. This paper, from the aspect of meaning, characteristics and current research circumstances of mobile learning, describes research results and research status of mobile learning at domestic and abroad, and states the theoretical significance of mobile learning on research of distance education. It aims to provide a reference for educators who engage in research of mobile learning and application of distance education.
\end{abstract}

Keywords- mobile learning; mobile education; distance education; learning style

With the rapid development of mobile communication technology, a new form of learning - mobile learning - has emerged. It is a new field of study, considered as a learning mode of future, or an indispensable learning mode of future learning.

\section{MEANINGS OF MOBILE LEARNING}

For mobile learning, there are three different kinds of awareness and understandings currently.

(1) Take the mobile learning as a form of distance learning. For an example, distance educator Desmond Keegan put up with the view that distance learning, digital learning and mobile learning are the three development stages of distance education.

(2) Believe that mobile learning is the expansion of digital learning. Its learning content is the same with that of digital learning. The only difference is that the way of acquiring information and knowledge is through mobile communication networks and mobile communication devices. For an example, a special research program of mobile learning called "MOB ILearn Action", conducted by the EU "Action and Research Program of Digital European", has made a definition for mobile learning.

(3) Conduct research from the perspective of cognition and learning. It thinks that from the perspective of content and form, mobile learning has no essential difference with digital learning and e-learning, but the features of mobility and context-related has made mobile learning become a new learning technology and way completely different from digital learning and internet learning, like the perspectives of research group of mobile learning in University of Birmingham, UK.
Overall, mobile learning is a new form of learning that learners can obtain educational information, educational resources and educational services by the use of wireless mobile communications network technology and wireless mobile communication devices (such as mobile phones, personal digital assistants, etc.).

\section{CHARACTERISTICS OF MOBILE LEARNING}

By combing and analyzing the above more authoritative domestic and abroad definitions of mobile learning, the author believes that the characteristics of mobile learning can be broadly summarized as follows:

\section{A. Mobile learning forms}

This is the most important feature of mobile learning. Learners can learn at any place without being limited by traditional fixed teaching place and fixed access points of wire line network. Learners can learn during the walking or in a moving car. Similarly, the learners are not limited by time, and they can learn at any time without subjecting to a fixed time. Learners can access online educational resources and do independent study anytime, anywhere without being limited by time or space. Similarly, teachers can conduct teaching anytime, anywhere without being limited by time or space. In short, learning space, learning tools, learning resources, learning supporters and learners are all movable.

\section{B. Wireless learning devices}

Technical equipment of mobile learning must have characteristics of supporting wireless transmission, which is determined by the mobility of learning form. In the mobile learning process, learners can only freely, easily and effectively transfer learning data through learning equipment that is wirelessly accessible to Internet.

\section{Ubiquitous}

This is a fundamental characteristic that M-learning is different from the E-learning. The so-called "ubiquitous" means that anyone can learn anything at anytime, anywhere and the unique advantages of M-learning is unmatched by other learning methods, greatly meeting the learning needs of "always online". It has also laid an important foundation for the role of M-learning in the future learning.

\section{Interactive learning process}

Technology basis of mobile learning is network communication technology and mobile computing technology. Digital learning information, transportation of resources and services can both take advantages of these technologies to achieve two-way communication. This 
interactive learning process will help improve academic performance and confidence of learners, form the learners' optimism for learning, develop learners' communication skills, and develop the learners' personality and so on.

In addition to these main features, it also includes customized (autonomy), personalized learning content, miniaturization of learning content, and integration, flexibility, timeliness, network, crossing-time-and-space, virtual nature of learning technology, etc.

\section{DOMESTIC AND FOREIGN RESEARCH ACTUALITIES}

\section{A. Foreign research actuality}

Foreign study of mobile learning is earlier than that of our country. They are mainly concentrated in economically developed countries of Europe and North America. Some research institutions who get support from companies will apply mobile learning to business training; others are sponsored by educational institutions, based on at school education, trying to improve the teaching and management by new techniques.

For foreign studies, they can be roughly divided into the following types of projects:

1) Mobile learning projects developed for different learning objects

M-learning project is a mobile learning project funded by EU. The project lasts two years, from October, 2001 to December, 2004. The project hopes to provide learning opportunities to the majority of citizens aged 16 to 24 by simple and convenient technique means. These citizens are out of school without finishing it because of various reasons. Their abilities' of reading, writing and counting are low, and are not eligible to participate in the training organized by society. Let's see if this project can cultivate their interest in learning, provide them with learning opportunities to increase employment opportunities by the mobile phones in the hands of the young.

2) Mobile learning projects developed according to different learning environments

Those who are relatively famous are classroom feedback system for classroom teaching and exploring experiment system for natural environment. Classroom feedback system is an interactive question and answer system based on a wireless network. In the classroom, students hold remote controls in their hands and receivers connected with a computer, and they can do class quizzes activities. The system feedbacks students' response data timely to teachers and teachers can diagnose students' learning effects immediately and make timely remedial measures.

\section{B. Domestic research actuality}

China started late in the field of mobile learning, but with the rapid development of China's mobile communication technology and network technology, number of researches of this area is also increasing. These studies can be classified into several different directions:

1) Research on the development of foreign mobile learning
The article "Mobile Learning - Review of Foreign Research Actuality", written by Liu Yu Jun and Ge Shufang of Shaanxi Normal University, describes current several different definitions of mobile learning, analyzes the current study situation and study results of foreign mobile learning.

2) Exploration on the characteristics and prospects of mobile learning

In the article "M-Learning: New Development of Education Technology in 21st Century", Bai Juan made some discussions about mobile technology's great impact on people's learning ways and discussions of the prospects of mobile learning. Besides, there is another article written by Huang Dequn, "Impacts of Mobile Learning Research on Distance Education".

(3) Research on mobile learning system

In the article "Research of Mobile Learning System Based on J2EE Architecture" written by $\mathrm{Hu}$ Xinhe, he explored the technical characteristics of the J2EE architecture, did systematic analysis and comparison of the issues involved in that from a technical aspect according to the current status of mobile learning platform. He also put up with a solution for mobile learning system based on J2EE architecture.

4) First domestic mobile learning project

At present, China's first mobile learning project is "Theory and Practice of Mobile Learning", undertaken by Center for Educational Technology, Peking University and a project from Ministry of Education. Dong Aiqin, Cui Guangzuo designed and realized a mobile learning platform based on handheld device by analyzing the characteristics of mobile learning in the article "A Modern Education Information Platform Based on Handheld Mobile Device".

Foreign and domestic researches show that, with the development of mobile communication technology, it is more convenient to apply wireless technology to education and training and capacity of mobile learning is also growing. From digital learning to mobile learning, from simple mobile learning to complex mobile learning, from general mobile learning to higher education, basic education, popular knowledge and education, we can see the application breadth of mobile learning.

\section{IMPACT OF THE STUDY OF MOBILE LEARNING ON DISTANCE EDUCATION}

For technology's entering the field of education, no matter it is e-learning or mobile learning, they are both new ways of teaching and learning by combining modern educational thought with related information technology, with no property of education forms. Thus, mobile learning can not only be applied to face-to-face education but also be applied to distance education. So, what does the applications of mobile learning in distance education exactly mean?

\section{A. New topic of forcing us to re-understand the theory of distance education}

One important theory of the forms of distance education is about the judgment made by the famous German scholar Peters on industrialized forms of distance education. In his article "Teaching Structure of Distance Education: Research 
on Highly Industrialized Form of Teaching and Learning", he pointed out that in distance education, teaching is highly industrialized, learning is also highly industrialized, and distance education is one of the products of this industrialized society. The only theoretical model applicable to the analysis of this new form of industrialized education is the industrial production theory. If the post system of correspondence distance education as well as radio and television of electronic distance education is the product of industrial society, then mobile learning network and future mobile learning terminal which are still in concept are certainly not the products of industrial society, but the products of information society. This is a denial for the industrial technology basis of Peters' theory about the forms of distance education.

Secondly, anytime and anywhere of mobile learning are definitely the characteristics of post-industrial society information society. The interactive learning activities between teachers and students that used to be limited by place and time will no more show the transfer process of "Teaching Production and Packaging". In addition, the results of "debris" experimental study in mobile learning are contrary to an important fulcrum of Peters' thesis - teaching process is sent as materials of distance learning after careful design, systematic development and mass production. Studies of Stanford Learning Lab (SLL) showed that when people are "moving", their efficiency is connected with the concentration of spirit. Learners conduct their learning activities in certain piecemeal time. New way of learning the connection between context and its transmission characteristics, brought by mobile learning are also different from the fixed, high-capacity learning styles. Mobile learning is a "debris" learning style, design of learning materials must be of fragmentation, and be focusing on the development of learning materials suitable for piecemeal time. Thus, the emergence of mobile learning approach gives us a new topic of forcing us to re-understand the theory of distance education.

\section{B. Make structure and process theory of distance education more distinct}

Theory of distance education structure starts from the system aspect, based on the analysis of the components of distance education's operation system and its role. The concise outcome of the theory of remote education structure is " 1233 ". The " 1 " refers to taking the students or study as the core; the "2" refers to that the basic operation system of distance education is composed of two parts i.e. curriculum and students; the first " 3 " stands for three elements. Distance education, just like face-to-face education, has three core elements i.e. teachers, students and teaching contents; the second " 3 " represents three kinds of interactive relationship of teachers, students and teaching contents. In the development process of theory of distance education structure, the teachers' status and relationship between teachers and students are always one of the focuses of theory research and debates. Considering from the concept of mobile distance learning at present, interaction between teachers and students should be a part of the theory of distance education structure.

Theory of distance education process have summarized basic laws and principles of teaching and learning activities under the condition of the relative separation between teachers and students, including contents of three parts i.e. independent learning, two-way communication and resynthesis of teaching activities. Independent learning theory, which has been influenced by the thought of social democracy education and free education philosophy, emphasizes the importance of independent learning and autonomy of students in the process of distance education; two-way communication theory expounds the interpersonal problems in distance education deeply and thinks highly of importance of successful study that result from effective communication between teachers and students and endows the independence of the learners' study with rich cultural and philosophical value. Comprehensive theory of the teaching activities points out that distance education should find their theoretical basis from the theory of general education theory and rebuild the scene of the interaction of teaching and learning which is across time and space. In the theory of distance education process, what has been debated for long time is that the main characteristic of the remote teaching process is autonomous learning or two-way communication, but it now appears that there will be no mobile learning without two-way communication. So, the theory of distance education process should not exclude the content of the two-way communication.

\section{Emergence of the fourth generation of distance education concept}

From a technical point of view, Canadian scholar Garrison, Danish scholar Nipper and British scholar Bates put forward the theory of the third generation of information technology and the third generation of distance education. According to their thinking, the use of mobile communication technology and the emergence of mobile distance learning should be the fourth generation of information technology and the fourth generation of distance education. In the article "From distance learning to elearning and then to mobile learning", Keegan defined the first and second generations of distance learning as Dlearning, and the third generation as E-learning.

\section{CONCLUSIONS}

Mobile learning is the inevitable result of the combination of mobile communication technology, network technology as well as the thought and theory of modern education. It will cause profound changes in education, especially distance education with the continues deepening of theoretical research and continues maturity of technology. We can see from the above analysis that the depth and breadth of the foreign research and application of mobile learning (mobile education) is far better than our country, and mobile learning, as a new thing, has just started in our country. So the research and application for mobile learning is not much. I believe that it will be of guiding significance for the research and applications of mobile learning to know 
the research dynamics of foreign mobile learning and summarize their research experience, dig new ideas, new methods and new technologies in their studies.

\section{REFERENCES}

[1] Desmond Keegan, Mobile Learning: the Next Generation of Learning [M].Dublin: Distance Education International,2005:138-139.

[2] Goh T.T., Kinshuk \& Lin T.(2003). Developing an adaptive mobile learning system. In K.T. Lee \& K. Mitchell (Eds.) Proceedings of the International computer in Education 2003 (December 2-5, 2003,
Hong Kong), Norfolk, VA, USA: AACE, 1062-1065(ISBN 1880094-51-7)

[3] Richard Nantel. How to Determine Your Readiness for Mobile Elearning [EB/OL].http://www.brandon-hall.com.2005-06-30

[4] Liu Yujun, etc. Mobile Learning - Review of Foreign Research Actuality [J]. Modern Educational Technology, 2004, (3) :12-16.

[5] Ye Chenglin, etc. Review of Mobile Learning Research [J]. e-Education Research, 2004, (3) :12-19.

[6] Ren Guangjie, Ding Xin. Research of Otto Peters [J].Chinese eEducation, 2004, 29(6):40-42.

[7] Ding Xingfu. Taxonomical Study and Major Achievements of Distance Education Forms [J]. Open Education Research, 2001, 29 (1). 